\title{
Health, education, and retirement over the prolonged life cycle: a selective survey of recent research
}

\author{
Michael Kuhn, Alexia Prskawetz and Uwe Sunde*
}

\section{Introduction}

This issue of the Vienna Yearbook of Population Research contains a selection of papers that were presented at the conference 'Health, Education, and Retirement over the Prolonged Life Cycle', which was organised by the Vienna Institute of Demography of the Austrian Academy of Sciences and held in Vienna in November 2013. The conference was devoted to the socio-economic causes and consequences at both the individual and the societal level of the unprecedented increase in life expectancy over the past few decades. At the micro level, a better understanding is needed regarding the extent to which the increase in human life expectancy has been shaped by individual health behaviour, rather than by other socio-economic influences, and through which channels this happened. Conversely, it is important to understand better how the prolongation of the life cycle will shape individual behaviour. The conference focused on behaviour relating to health, education, and the supply of labour.

Although generally perceived as a positive development, the increase in life expectancy also poses policy challenges for social security and the cohesion of society, given that different social groups benefit from rising longevity to varying degrees. Important questions have been raised about the macro consequences of the prolongation of the individual life cycle, not least because having an understanding of the underlying mechanisms will be crucial for assessing the extent to which retirement, health, and educational policies need to be reformed. The recognition that the design of reforms should be guided by an awareness of the potential effects

\footnotetext{
${ }^{*}$ Michael Kuhn (corresponding author), Wittgenstein Centre (IIASA, VID/ÖAW, WU), Vienna Institute of Demography, Welthandelsplatz 2, Level 2, 1020 Vienna, Austria

Email: michael.kuhn@oeaw.ac.at

Alexia Prskawetz, Institute of Statistics and Mathematical Methods in Economics, TU Wien and Wittgenstein Centre (IIASA, VID/ÖAW, WU), Vienna Institute of Demography, Vienna, Austria Uwe Sunde, Seminar for Population Economics, University of Munich, Munich, Germany
} 
Health, education, and retirement over the prolonged life cycle

of policies on individual life-cycle behaviour closes the circle of topics addressed in this volume.

The remainder of this introduction sets the scene for the articles contained within this volume by presenting the editors' (subjective and selective) take on the state of research regarding the link between longevity and individual life-cycle behaviour relating to health, education, and retirement.

\section{Health, health behaviour, and the prolonged life cycle}

This sub-section presents a brief review of some of the recent debates on the role of health in the extension of the life course. After providing an overview of the debate on the extent to which reductions in mortality are accompanied by reductions in morbidity, we highlight the roles of health behaviours, education and social context in shaping health and longevity.

\subsection{The debate on healthy life expectancy: demographic and economic perspectives}

Since the 1980s there has been a heated debate among demographers and epidemiologists about the relationship between life expectancy and morbidity, and the implications of this relationship for the quality of life experienced by ageing populations. Central to this debate are the following questions: Is increasing life expectancy accompanied by a compression of morbidity, and thus by a more than proportional increase in healthy life expectancy (Fries 1980)? Alternatively, is mortality accompanied by an expansion of morbidity (Gruenberg 1977)? Moreover, is it possible that morbidity and mortality are jointly determined by physiological processes that govern both the incidence and severity of disease (Manton 1982)? This debate is on-going (see, e.g. the survey by Crimmins and Beltran-Sanchez (2010)). While recent studies based on aggregated data provide evidence that healthy life expectancy has been increasing (e.g. Cai and Lubitz 2007), a much more complex picture emerges when the different dimensions of health are considered (e.g. Crimmins 2004, Crimmins and Beltran-Sanchez 2010). Generally, it appears that while the prevalence of chronic conditions among the elderly has increased, the extent to which these conditions lead to disability has declined (Freedman et al. 2007). Recent evidence also shows that the trend in the increase in healthy life expectancy may have recently started to reverse, at least in the US. One prime suspect in this context is the increased prevalence of obesity (Lakdawalla et al. 2004; Martin et al. 2009, 2010). At the same time, there is clear evidence of a widening educational gap in longevity gains in the US (Meara et al. 2008; Baker et al. 2011; Montez et al. 2011, 2012; Brown et al. 2012), with the longevity gains concentrated among those with the highest levels of education. 
Cutler et al. (2006) surveyed the historical and the current mechanisms behind the longevity expansion in both developed and developing countries. As the main drivers they identified a complex nexus of pathways, including access to health care and medical progress, the provision of public health infrastructure and education, behavioural factors, family and social background reaching back into early childhood, and social structures. Specific sources of longevity expansion can be identified at the disease level. Ford et al. (2007), for instance, showed that about $47 \%$ of the reduction in US mortality from coronary disease between 1980 and 2000 was explained by changes in treatments, while $44 \%$ of the decline was attributable to changes in medical and behavioural risk factors.

Focusing on behaviour, economists have conceptualised the relationship between health and longevity as being the (joint) outcome of a life-cycle decision problem in which individuals are able to influence their health and their survival by consuming health care and adopting lifestyles conducive or detrimental to health. Refining the seminal model by Grossman (1972), economists have endogenised life expectancy (Ehrlich and Chuma 1990) and mortality (e.g. Ehrlich 2000, Kuhn et al. 2011, 2015), making them functions of deliberate health investments. While models in the tradition of Grossman (1972) have assumed that health investments contribute to an increase in the stock of health (Ehrlich and Chuma 1990) or to a reduction in the rate of health decline (Kuhn et al. 2015), Dalgaard and Strulik (2014) and Strulik (2015) have recently modelled the 'reverse' process through which individuals invest in factors that delay the accumulation of deficits linked to frailty and a higher risk of mortality (Rockwood and Mitnitski 2007).

\subsection{Health behaviour along the prolonged life course}

Generally, the willingness to spend more resources to improve the chances of survival is measured as the (statistical) value of life, a metric of the (monetary) value assigned to the stream of utility and income over the remaining life course (e.g. Shepard and Zeckhauser 1984, Ehrlich and Chuma 1990, Ehrlich 2000, Murphy and Topel 2006, Becker 2007, Hall and Jones 2007, Birchenall and Soares 2009, Kuhn et al. 2010, 2011, 2015). The value of life is generally assumed to increase with the length of the remaining life time; with the quality of the remaining life, as measured by the benefits from consumption, leisure, and health; and with the value assigned to descendants. Murphy and Topel (2006) have made the important case that medical advances that have led to a reduction in mortality from causes such as coronary heart disease have also increased the willingness of people to pay for a reduction in competing mortality risks, such as cancer (see also Dow et al. 1999, Becker 2007). A similar complementarity exists between treatments aimed at extending the 'quantity of life' and those aimed at improving the quality of life (e.g. treatment of Alzheimer's disease). The concept of complementarities along the life course extends to investments in education (Becker 2007): i.e. avoiding the loss of human capital or the capacity to benefit from it due to morbidity or premature 
mortality constitutes a return on health investments, whereas health and longevity boost the returns on education.

Surprisingly, there are very few empirical studies based on individual-level data, as van Baal et al. (2013) pointed out in a survey on the relationship between health expenditure and longevity. ${ }^{1}$ Among this handful of studies is an analysis by Cutler (2007). His examination of the impact of cardiac revascularisation on individual survival showed that revascularisation raises a patient's remaining life expectancy by about one year at a cost of USD 40,000.

In contrast, there is a large body of literature on the relationship between health behaviour-or 'lifestyle', as it is often called - and health outcomes, including morbidity. Referring readers to the recent surveys by Strauss and Thomas (2007) and Cawley and Ruhm (2011), we focus on a few selected studies to illustrate recent developments in research on this topic. While the positive association between health, longevity, and socio-economic status (SES) is widely accepted, it is notoriously difficult to establish causal relationships within the nexus of income, education, and health; as these characteristics tend to be jointly determined (Adams et al. 2003). A life-cycle perspective is helpful in a number of ways: conceptually, life-cycle models make transparent how health outcomes and income, as well as the underlying stocks of 'health capital' and assets, develop jointly over the life cycle as a consequence of prior choices related to health, education, and saving. In principle, these models then allow us to determine how the life-cycle allocation is shaped by the initial endowment of wealth, health, and ability, including genetic disposition and, depending on the focus, (early) childhood experience. Empirically, the panel structure of individual life-cycle data facilitates an identification of the causal effects in this context.

Adams et al. (2003) used the US Asset and Health Dynamics of the Oldest Old (AHEAD) panel to test for the absence of causal links between SES and health changes and mortality. They found that among the elderly population, who are typically covered by Medicare health insurance, there is no direct causal link between SES on the one hand and mortality and acute health conditions on the other, once initial health is taken into account. It is, however, possible that there is a causal link between SES and conditions with a gradual onset, such as mental conditions and some degenerative and chronic conditions. Applying dynamic panel methods to British Household Panel data, Contoyannis et al. (2004) established the presence of a strong positive state dependency for health and unobserved permanent heterogeneity, which accounts for around $30 \%$ of the unexplained variation. Based on these findings, they argued that mean income, as a measure of permanent income, has a stronger impact on health than transitory fluctuations in current income. Using data from the British Health and Lifestyle Survey, Balia and Jones (2008) estimated a recursive model of mortality, morbidity, and lifestyles. They found that

1 Studies at macro level typically identify a weak yet significant impact (e.g. Cremieux et al. 1999, Lichtenberg 2004, Hall and Jones 2007, Martin et al. 2008, Baltagi et al. 2012). 
behaviour, and particularly behaviour related to smoking and sleeping patterns, has a significant impact on predicted mortality; whereas SES measures play a reduced role. Rosa Dias (2010) used data from the UK's National Child Development Study to estimate how initial circumstances, which are beyond the control of the individual, determine health outcomes by affecting the individual's lifestyle 'effort'. ${ }^{2}$ While social development during childhood and educational opportunities strongly shape the lifestyle of adults, the analysis also showed that unobserved heterogeneity drives both lifestyle choices and health outcomes. These results corroborate the assumption that parental and early childhood circumstances are important determinants of adult health behaviour and outcomes. Examining the impact of smoking on mortality, Adda and Lechene (2013) provided support for the notion that an individual's willingness to invest in health is governed by his or her survival chances: the analysis showed that individuals who are in relatively poor baseline health are more likely to start smoking and to smoke heavily. Finally, Fichera and Sutton (2011) and CobbClark et al. (2014) provided evidence that health behaviours are shaped by both health policy and personality traits, such as self-control.

A large body of empirical literature in demography and epidemiology has documented a positive association between education and health (Grossman 2008). Recent research has sought to identify the causal pathways of this association (Meara et al. 2008; Baker et al. 2011; Kunst et al. 2010; Montez et al. 2011, 2012; Brown et al. 2012). Indeed, we would expect to observe that education has a positive impact on health because of both the high marginal benefit associated with the lifecycle complementarity between health and education, and the low marginal cost of investing in health care for the highly educated. ${ }^{3}$ Using exogenous variation in education, recent studies have generated mixed support for a causal role of education in driving health and health behaviours: while Lleras-Muney (2005) found a strong negative impact of education on mortality in the US, a similar effect was not confirmed for France (Albouy and Lequien 2008) or for the UK (Clark and Royer 2013). However, using European data from the Survey of Health and Retirement (SHARE) in Europe, Brunello et al. (2015) found a positive impact of education on self-reported health. Cutler and Lleras-Muney (2010) identified a strong educational gradient in a large set of health-related behaviours for the US; a result that is in line with earlier US findings on smoking (Currie and Moretti 2003, Kenkel et al. 2006, De Walque 2007, Grimard and Parent 2007), but not on obesity (Kenkel et al. 2006). While variations in exogenous measures of education do not appear to explain health behaviours in a number of European settings (Reinhold and Jürges 2009, Braakman

\footnotetext{
2 The study ties in with a larger literature on the role of equality in opportunity in health care (e.g. Rosa Dias 2009; Trannoy et al. 2010; Balia and Jones 2011; Jusot et al. 2013; Garcia-Gomez et al. 2014; Jones et al. 2014).

3 Glied and Lleras-Muney (2008), for instance, found that the educated tend to benefit disproportionately from mortality-reducing medical innovations. Presumably this is because, compared to people with less education, highly educated people have better information, which in turn reduces the cost of accessing these technologies.
} 
2011, Kemptner et al. 2011, Clark and Royer 2013), Brunello et al. (2015) identified significant behavioural effects when decomposing the impact of education on selfreported health.

According to findings by Cutler and Lleras-Muney (2010) and Conti and Hansman (2013), cognition and personality during childhood play important roles in determining the extent to which education feeds into health and health behaviours. These findings are in many ways consistent with the results from a Danish twin study, which found that the education-health gradient is not causal, but is instead related to the children's social and genetic endowment (Behrman et al. 2011). In a similar vein, Auld and Sidhu (2005) studied the impact of schooling on health, conditional on the level of schooling and cognitive ability; and found that schooling has a causal effect on health only among individuals with low levels of schooling and ability. Indeed, as Montez and Friedman (2015) argued in their introduction to a special edition of Social Science and Medicine (Vol. 127) on educational attainment and health, the education-health gradient is context dependent: for instance, the gradient is more pronounced when education and knowledge are more relevant because of the prevailing social and (advanced) technological conditions (e.g. Hayward et al. 2015), in disadvantaged contexts, and at the bottom end of the education distribution (e.g. Gathmann et al. 2015, Hayward et al. 2015).

\subsection{Health and ageing within social networks}

Individuals are embedded in social networks of family, friends, colleagues, and neighbours; and these networks affect health and health behaviour through social influence, the provision of social support and social capital, and the transmission of both diseases and information (see Luke and Harris 2007 and Smith and Christakis 2008 for surveys). The analysis of network effects is not typically conducted within a life-cycle setting, although life-cycle effects should clearly be expected. First, peer effects during childhood and adolescence determine health behaviours over long periods of an individual's life course (Harris 2010), and particularly addictive or habitual behaviours, such as smoking, drinking, and eating habits (e.g. Auld 2005, Powell et al. 2005, Clark and Loheac 2007, Nakajima 2007, Harris and LopezValcarcel 2008, Trogdon et al. 2008, Fletcher 2012, Mora and Gil 2013). To the extent that an individual enters into and remains within a (homophilous) network of like-minded peers and family (e.g. Clark and Etile 2006, 2011), these habits may persist over the life course. Second, the selection into certain networks is likely to determine the level of support an individual receives when his or her health deteriorates. Thus, for example, marriage has been shown to have a protective effect (e.g. Grundy and Sloggett 2003, Gardner and Oswald 2004, Murphy et al. 2007). Finally, the networks an individual belongs to are prone to change over the life course (e.g. Wenger et al. 2000, Ajrouch et al. 2005), which implies that individuals tend to be exposed to age-specific social influences on their health and their health 
behaviour. These considerations suggest that an integration of the elements of network and life-cycle analysis is needed.

\section{Human capital, education, and the prolonged life cycle}

This subsection provides a brief review of the recent debate on the implications of the prolonged life cycle for education and human capital acquisition. We end by pointing to some implications for long-run development.

\subsection{The conventional view of life expectancy and education}

Education and, more broadly, the acquisition of human capital are investment activities that can involve immediate costs for the individual. Education-related expenses include opportunity costs with respect to labour market participation, as well as resource costs such as tuition. The benefits of education, which typically come in the form of increased productivity and returns on the labour market, do not accrue to the individual until after the completion of education. As with any investment, the total expected return depends on the length of the amortisation period, which in the context of education hinges on the length of life. The earliest formal treatments of this insight go back at least to Mincer (1958), who pointed out the crucial role of the length of the work life in making an optimal decision about the amount of time spent in education and training. In a reduced form, similar arguments were made by Gary Becker, who noted that "the influence of life span on the rate of return [to human capital] and thus the incentive to invest is important $(. .$. the longer is the expected life span and the larger is the fraction of a lifetime that can be spent at any activity". (Becker 1964[1993], p. 86). Ben Porath (1967) developed a formal model of the optimal allocation of education decisions over the life cycle and the corresponding earnings path that used a deterministic time horizon. In this model, the length of life was considered the crucial determinant of any investment in human capital. It was thus long seen as a truism that the increase in longevity over the past two centuries was a central force behind the massive increase in educational attainment observed over the same period.

A direct implication of this view is that the prolongation of life and the associated increase in educational attainment had important consequences for (human capitaldriven) growth and development (see, e.g. de la Croix and Licandro 1999, KalemliOzcan et al. 2000, Boucekkine et al. 2003, Lagerlöf 2003, Soares 2005, and Cervellati and Sunde 2005, 2015a). 


\subsection{The debate on longevity, life-time labour supply, and education}

The argument that the increase in life expectancy played a central role in the sharp rise in educational attainment has been debated recently. This debate began with the work by Hazan (2009), who argued that in the Ben Porath model, a necessary condition for the prolongation of life to cause a higher investment in education is an increase in life-time labour supply. He then showed that life expectancy and educational attainment had increased across consecutive cohorts of American men born between 1840 and 1970, and for American individuals born between 1890 and 1970; but that life-time labour supply had actually decreased along both the extensive and the intensive margins, which arguably violates this necessary condition. This contradiction of the conventional wisdom sparked a debate about the role of life expectancy in educational attainment at the macro level. Hansen and Lonstrup (2012a) showed that these empirical patterns can be reconciled using a model with imperfect financial markets in which an increase in life expectancy can lead to both an increase in the amount of time spent in education and a reduction in life-time labour supply, because individuals can afford to retire earlier as a result of their higher life-time earnings and savings. Complementary work by d'Albis et al. (2012) suggested that the incentives for earlier retirement might also depend on whether the mortality decline that causes life expectancy to increase affects people at younger or older ages.

Cervellati and Sunde (2013) studied a generalised Ben Porath model with a realistic survival law, and demonstrated that, in general, an increase in life-time labour supply is neither a necessary nor a sufficient condition for an increase in life expectancy to cause an increase in educational attainment. In fact, in this model the life-time labour supply is the central factor in the marginal benefits of education. However, a reduction in benefits does not necessarily mean that the optimal educational level cannot be higher, because the marginal costs might also have fallen with life expectancy. Using the same data as Hazan, they found that the progressive rectangularisation of the survival curve, which was responsible for the prolongation of life over the past 150 years, led to changes in both marginal benefits and marginal costs. Overall, their evidence does not call into question the assumption made in a generalised Ben Porath model that longer life expectancy is a necessary condition of increased educational attainment. Recent work by Bonneuil and Boucekkine (2014) has suggested that the relationship between longevity and the optimal length of education might depend on the age distribution of mortality rates. Sanchez-Romero et al. (2015) provided conditions under which a decrease in mortality leads to a longer period of education and an earlier retirement, which can be decomposed into a Ben Porath mechanism; i.e. a wealth effect and a years-toconsume effect. 


\subsection{Longevity and schooling: macro-level evidence}

Empirical evidence at the macro level supports the view that the effect of life expectancy on education might not be homogeneous. Hazan (2012) found that increases in life expectancy at birth between 1960 and 1990 were positively correlated with the increase in educational attainment across the world, whereas the increase in life expectancy at age five exhibited only a weak relationship with schooling. A potential reason for this apparent contradiction is heterogeneity in the decline of age-specific mortality that underlies the increases in life expectancy affected, as some of the theoretical contributions mentioned above have suggested. Moreover, the incentives to invest in education might depend on the demographic development of a country. In particular, the demographic transition constitutes a turning point for population dynamics, as the fertility decline in the later phases of the demographic transition frees up resources that households can devote to education. Hence, improvements in life expectancy are likely to deliver more pronounced increases in educational attainment after the fertility transition has commenced, and as long as the decline in mortality rates affects individuals of working ages. Using cross-country panel data from the international epidemiological transition of the 20th century to identify the causal effects of life expectancy on education and population dynamics, Cervellati and Sunde (2015b) found evidence that supports the hypothesis of a heterogeneous effect. This finding is complemented by evidence reported by Hansen (2013), who examined data from medical breakthroughs in the 1940s and 1950s. His findings indicate that the rise in life expectancy, and in particular the improvement in childhood health, was responsible for a significant part of the increase in human capital over the second half of the 20th century. Using a calibration exercise, Sanchez-Romero et al. (2015) showed that a combination of a Ben Porath mechanism and a wealth/yearsto-consume effect can account for the dynamics among the Swedish birth cohorts between 1865 and 2000 .

\subsection{Longevity and schooling: micro-level evidence}

The aggregate evidence suggesting that life expectancy and health play important roles in educational outcomes is consistent with recent micro evidence. Using data from the hookworm eradication in the US south around 1910, Bleakley (2007) found that the substantial and immediate reduction in disease prevalence led to substantial increases in school enrolment, school attendance, and literacy. Jayachandran and Lleras-Muney (2009) examined the effects of the reduction in maternal mortality in Sri Lanka between 1946 and 1953, which led to a significant increase in life expectancy among school-age girls. They found that female literacy and years of education increased as a result of this rise in life expectancy. Recent work by Oster, Shoulson, and Dorsey (2013) has suggested that the expected length of life appears to influence decisions about education. They used variation across individuals who 
have ex-ante identical risks of the outbreak of Huntington disease, an inherited neurological disorder, but who differed in terms of whether they were actually affected by the disease and thus expected to have a shortened life span. They found that the individuals with the mutation that leads to the outbreak of the diseases completed less education and job training.

\subsection{Interactions with other margins: fertility, labour force participation, and health feedbacks}

The shift in decisions regarding education caused by a prolongation of life also interacts with behaviour in other domains. As we discussed above, the mortality decline in the early stages of the demographic transition was followed by a decline in fertility and a slow-down in population growth, which was in turn accompanied by increased participation in schooling. Using micro evidence from Brazil, Soares (2006) found that higher longevity is systematically associated with higher educational outcomes and lower fertility. Similarly, Bleakley and Lange (2009), also using data on the hookworm eradication in the US south around 1910, found that the ensuing increase in educational attainment was accompanied by a significant decline in fertility. Soares and Falcao (2008) suggested that, through changes in educational incentives and fertility, the prolongation of life might have changed female labour force participation and narrowed the gender wage gap.

Another important implication of increased schooling is the feedback to health and life expectancy. This feedback might have been an important factor in the transition from stagnation to growth (Cervellati and Sunde 2005, 2015a). The evidence discussed above shows that changes in education resulting from compulsory schooling legislation and other factors had causal effects on health behaviour and mortality decline.

\section{Retirement and the prolonged life cycle}

In parallel with the sharp increase in life expectancy, the labour supply at both young and old ages has been declining since the 1960s in most of the OECD countries. The decline in the labour supply at younger ages was related to the extension of education and the corresponding later entry into the labour market, while the decline in labour supply at higher ages was related to a trend towards early retirement. The average retirement age in the OECD countries was 68 in 1970, and had declined to age 64 by 2010 (OECD 2009).

In an effort to reconcile these findings with economic theory, a number of authors have pointed out that increases in life expectancy were accompanied by rising income. Since consumption and leisure are both normal goods, an increase in income may also be associated with an increase in the demand for leisure; i.e. retirement (Costa 1998). However, many other factors affect the labour supply as 
well, and the final question boils down to whether the value of leisure becomes higher than the value of work when life expectancy increases (Lazear 1986).

In a series of papers, Gruber and Wise $(1998,2004)$ studied the role social security programs play in early retirement. They showed that the present value of social security benefits declines with the retirement age, and that the implicit tax rate on wage income at old age is quite high, which tends to push workers out of the labour market once they have reached the age of pension eligibility. In most European countries the wage adjustments associated with early retirement are not actuarially fair. Moreover, social programs like unemployment and disability insurance support retirement at ages below the normal retirement age. Consistent with this view, Eichhorst (2011) showed that the core factors that drive the cross-national diversity in retirement behaviour are differences in both institutional arrangements and social and labour market policies. Various studies have indicated that limiting the incentives for early retirement, increasing the statutory retirement age, reducing the generosity of unemployment benefits, and lowering income taxes and non-labour wage costs can foster employment among older workers.

In addition to these institutional factors, Phillipson and Smith (2005) have argued that poor health, disability, and work-related stress may lead individuals to exit the labour market early. Measures that can help keep people in the work force as they age include providing older workers with on-going training and skills development, as well as with flexibility in terms of their work schedules and responsibilities.

The reduction in the retirement age has also been attributed to changes in technology, and to age-specific differences in productivity. The lower productivity of older workers may lead firms to lay off employees before they reach the normal retirement age. Ferreira and Pessoa (2007) have argued that the retirement age may fall further as longevity increases, because older workers may become obsolete in periods of rapid innovation.

Theoretical models that aim to reconcile the observed increase in life expectancy and the parallel decrease in the retirement age have offered various alternative explanations. One central argument, put forth by Kalemli-Ozcan and Weil (2010), is that uncertainty about the date of death plays a role in the decision about how to balance labour supply and leisure. Increases in life expectancy are accompanied by less uncertainty about the date of death, which may be expected to induce individuals to save for retirement and to avoid working until they die. Based on work by Gruber and Wise (2004), Heijdra and Romp (2009) have shown that in an OLG model with realistic mortality patterns, the effect of greater longevity on optimal endogenous retirement age is ambiguous, and will depend on the prevailing fiscal and pension system. Bloom et al. (2003) argued that the effect of increases in life expectancy on retirement may be less than proportional, and pointed out that an increase in longevity accompanied by reductions in morbidity may also induce people to work longer. Recently, several authors have shown that the age pattern of the mortality decline may play a decisive role in whether the retirement age decreases or increases with longevity. In particular, it has been shown that mortality declines during adulthood may cause earlier retirement, while reductions 
in mortality at older ages may lead to delayed retirement (d'Albis et al. 2012, and Strulik and Werner, 2012). The trend towards earlier retirement caused by a decline in adult mortality may be explained by the increase in the expected lifetime human wealth effect when mortality at working ages decreases. Hansen and Lonstrup (2012b) offered another complementary theory to explain the relationship between life expectancy and the fall and rise in the retirement age. For low levels of life expectancy, they supported the uncertainty effect of increased longevity laid out in Kalemli-Oczan and Weil (2001). They argued that when levels of life expectancy rise, fewer unintended bequests are transferred to the succeeding generations, who in turn have lower incomes and are less able to save. Consequently, these generations may be expected to retire later. Like the model of Kalemli-Ozcan and Weil (2010), their model lacks an annuity market. While most of the existing theoretical models have studied partial equilibrium effects, Prettner and Canning (2014) examined the interdependencies between savings, interest rates, and optimal retirement decisions; and how these decisions respond to both increases in longevity and changes in technological progress. Since longevity increases saving rates, interest rates also decline; thus, the effect on retirement is ambiguous. While decreasing interest rates may induce individuals to work longer, the lower compound interest rates on their life-time labour income may lead them to retire earlier. In addition to these two indirect effects, the authors identified two direct effects: higher life expectancy may reduce incentives to work, and working longer may imply higher life-time consumption. By fostering economic growth, technological progress will boost lifetime income and hence the demand for leisure. At the same time, however, higher wages may induce older workers to retire later. Prettner and Canning concluded by showing that the parameter restrictions of the model that implies that the retirement age will increase as a consequence of longevity are fulfilled in Europe. However, these results will hold only as long as public pension systems do not introduce incentives for early retirement.

In addition to these changes at the extensive margin of labour supply, increases in longevity may affect the intensive margin by influencing the number of hours worked. Restuccia and Vandenbroucke (2013) showed that increases in wages and life expectancy account for $88 \%$ of the decline in the number of hours worked between the 1870 and 1970 birth cohorts in the US. However, life expectancy alone accounts only for $3 \%$ of the decrease in working hours. Restuccia and Vandenbroucke (2014) also demonstrated that the decline with rising income in the number of hours worked is more pronounced in poor countries.

\section{Structure of the Vienna Yearbook 2014}

The present issue of the VYPR contains seven original articles that are closely related to and extend the literature surveyed above. The first two chapters contribute to the literature on health and health behaviour and to the literature on retirement, and establish interesting links between these two fields of study. 
The first chapter, authored by Heather Booth, Pilar Rioseco and Heather Crawford, deals with the role of demographic differences in the association between social networks (SN), social support (SS), and self-rated health (SRH) among the elderly population. The authors argue that demography is likely to shape this relationship in at least three dimensions: first, the family status of an individual delineates his or her social networks of kin and friends; second, these networks evolve and change with demographic events (marriage, widowhood, etc.) over the life cycle, which implies that the networks of the elderly depend on earlier life course events; third, the impact of the SN and the SS structures on self-rated health is prone to vary across (demographic) subgroups of the population. Using survey data from Australia, the authors explore the extent to which a positive association between social networks and self-related health is driven by reverse causation, and how the causal and reverse-causal effects vary across demographic subgroups. Starting with the full sample, they study the association across distinct 'healthy' and 'unhealthy' subgroups, assuming that reverse causation (i.e. restricted access to social networks due to ill health) should not matter for the healthy. Their findings suggest that reverse causation tends to play a large role overall, as it explains most of the association between social networks and self-reported health among the unhealthy; while the positive relationship among the healthy varies with the demographic context. Based on their exploratory evidence, the authors highlight potential channels through which the SN/SS-SRH relationship is expressed among the different sub-groups.

In the second chapter, Lucia Coppola and Daniele Spizzichino use EU-SILC data for Italy to study the impact of retirement on self-reported health. Focusing on the role of gender, they argue that in light of the persistence of traditional family role models (male breadwinner, female housewife, and second earner) in Italy, the effects may differ considerably across male and female retirees: i.e. while retirement may lead to a worsening of self-reported health due to the stress associated with the reorganisation of lifestyles and family roles after retirement, the opposite may be the case for women who were previously struggling to reconcile work and family roles. Applying propensity score matching methods for identification, the authors find that while retirement has a negative short-term impact on male health, it has no significant effects on female health. This result may be viewed as partial confirmation of their hypothesis. Their findings suggest that recent reforms of the Italian pension system, which have predominantly affected women's retirement, should not have a strong offsetting effect on health expenditures. However, the authors conclude by noting that further research is needed to determine the longrun impact of retirement on health and to investigate in greater depth the effects of pension reforms on the health-retirement nexus.

The three chapters that follow are related to the literature on the link between ageing, labour supply, and retirement. These chapters highlight the changing roles of leisure, socio-economic status, education, and social networks for labour supply and retirement. The third chapter authored by Haodong Qui, presents new estimates on the relationship between labour supply and wage dynamics in Sweden for the time 
period 1985-2003. As population ageing will require an extension of the labour supply among the working-age population, it is important that we gain a better understanding of how the age-specific labour supply reacts to changes in the wage structure. According to the inter-temporal substitution hypothesis (ISH), labour supply and wages should be positively correlated over the life cycle. However, empirical estimates at the micro and the macro levels are so far not conclusive. The innovation by Haodong Qui is to apply recent data from the National Transfer Accounts to yield age-specific values for the ISH at the macro level. While the values he estimates are, in aggregate, quite close to those found in the literature, he shows that the variation across ages is quite high. Qui therefore argues that calibrations of overlapping generation economies need to take into account the lifecycle patterns of the labour supply elasticities.

The fourth chapter, contributed by Madelin Gómez-León and Pau MiretGamundi, investigates the role of socio-economic determinants for early retirement in Spain during the period 1999-2012 based on data from the Spanish Labour Force survey. As Spain has one of the oldest populations in Europe and one of the lowest labour force participation rates among the elderly, it is important that we gain a better understanding of the socio-economic characteristics that are associated with early labour market exit in Spain. The study focuses on the role of family arrangements in early retirement. The results clearly indicate that there is a strong gender division in the Spanish labour market, with men being more active than women. In terms of family structure, women are more likely to retire if they live with dependants (e.g. parents), while men are more likely to retire if they have a partner. The trend towards early exit from the labour market appears to be slowing among women but accelerating among men. Since education is positively correlated with working longer, investing in training and qualifications for adults may help to keep them in the work force longer.

In the fifth chapter, Linda Kridhal investigates the role of leisure activities for retirement using Swedish longitudinal data over the period 1981-2010. Since engaging in leisure activities is associated with having an active and healthy life, postponing retirement may be expected to have detrimental effects on retirees' activity and health levels. If period is not controlled for there is a clear association between engagement in specific leisure activities (e.g. cultural activities, gardening) and early retirement. However, once a period effect (representing labour market or pension policies) is controlled for, the empirical estimates indicate that those who are more engaged in leisure activities before retirement are not entering retirement significantly earlier. The author notes that future research may examine whether retirement timing is related to whether the leisure activities are physical, social, or intellectual. The results also show that leisure activities before and after retirement are quite similar.

The final two chapters link the literature on labour supply and retirement to institutional aspects and highlight broader implications of a prolonged life cycle for society. In the sixth chapter, Gustavo de Santis examines the properties of so-called Almost Ideal Pension Systems (AIPS), which are pay-as-you-go schemes for which 
the relevant policy parameters are set in relative rather than in absolute terms. The relative policy variables include, in particular, the relative shares of the life course spent working and in retirement, the standard of living afforded to children and pensioners relative to that of the working-age population, and the weight attached to actuarial fairness as opposed to intra-generational redistribution. The author shows how the design of these schemes renders the AIPS resilient to demographic and economic change. Using numerical exercises, he illustrates how AIPS compare with more conventional pension schemes (defined contribution, defined benefit, and risk-sharing) in terms of cross-sectional relative welfare, intergenerational equity, and contribution rates. The author finds that the AIPS outperform the conventional schemes in most respects. While these findings are subject to the stylised nature of the analysis, they help to identify in a structured way some of the weaknesses of real-world pension schemes.

In the final chapter of this volume, Josh Goldstein and Ronald Lee relate the on-going process of population ageing to the inequality of wealth in a society. The authors study three channels through which population ageing may affect inequality of income and of net worth: the increase in capital intensity under a slowdown of population growth; the shift in the age structure towards older and typically more unequal cohorts; and the impact of a longer life cycle on earnings and on the accumulation of capital. Employing US data, they find that a slowdown in population growth by one percentage point is expected to raise the income share of the top decile from 50 per cent to about 55 per cent-which represents a considerable increase in income inequality - merely through the increase in capital intensity. While the other two channels give rise to weaker effects, the authors conclude that, overall, the process of population ageing is likely to be accompanied by a sizeable increase in economic inequality.

\section{References}

Adams, P., M.D. Hurd, D. McFadden, A. Merrill and T. Ribeiro 2003. Healthy, wealthy, and wise? Tests for direct causal paths between health and socioeconomic status. Journal of Econometrics 112: 3-56.

Adda, J. and V. Lechene 2013. Health selection and the effect of smoking on mortality. Scandinavian Journal of Economics 115: 902-931.

Ajrouch, K.J., A.Y. Blandon and T.C. Antonucci 2005. Social networks among men and women: the effects of age and socioeconomic status. Journal of Gerontology B60: S311S317.

Albouy, V. and L. Lequien 2009. Does compulsory education lower mortality? Journal of Health Economics 28: 155-168.

Auld, M.C. 2005. Causal effect of early initiation on adolescent smoking patterns. Canadian Journal of Economics 38: 709-734.

Auld, M.C. and N. Sidhu 2005. Schooling, cognitive ability and health. Health Economics 14: 1019-1034. 
Baker, D.P., J. Leon, E.G.S. Greenway, J. Collins and M. Movit 2011. The education effect on population health: a reassessment. Population and Development Review 37: 307-332.

Balia, S. and A.M. Jones 2008. Mortality, lifestyle and socio-economic status. Journal of Health Economics 27: 1-26.

Balia, S. and A.M. Jones 2011. Catching the habit: a study of inequality in opportunity in smoking-related mortality Journal of the Royal Statistical Society A174: 175-194.

Baltagi, B.H., F. Moscone and E. Tosetti 2012. Medical technology and the production of health care. Empirical Economics 42: 395-411.

Becker, G. 1993. Human capital: a theoretical and empirical analysis. Third edition, University of Chicago Press.

Becker, G.S. 2007. Health as human capital: synthesis and extensions. Oxford Economic Papers 59: 379-410.

Behrman, J.R., et al. 2011. Does more schooling reduce hospitalization and delay mortality? New evidence based on Danish twins. Demography 48: 1347-1375.

Ben Porath, Y. 1967. The production of human capital and the life cycle of earnings. Journal of Political Economy 75(4): 352-365.

Birchenall, J.A. and R.R. Soares 2009. Altruism, fertility, and the value of children: health policy evaluation and intergenerational welfare. Journal of Public Economics 93: 280-295.

Bleakley, H. 2007. Disease and development: evidence from hookworm eradication in the American South. Quarterly Journal of Economics 122(1): 73-117.

Bleakley, H. 2010. Health, human capital, and development. Annual Reviews in Economics 2: $283-310$.

Bleakley, H. and F. Lange 2009. Chronic disease burden and the interaction of education, fertility and growth. Review of Economics and Statistics 91(1): 52-65.

Bonnueil, N. and R. Boucekkine 2014. Longevity, age structure, and optimal schooling. Aix-Marseille School of Economics Working Paper 2014-49.

Bloom, D.E., D. Canning and B. Graham 2003. Longevity and life-cycle savings. Scandinavian Journal of Economics 105(3): 319-338.

Bloom, D.E., D. Canning, R.K. Mansfield and M. Moore 2007. Demographic change, social security systems, and savings. Journal of Monetary Economics 54: 92-114.

Bloom, D.E., D. Canning and M. Moore 2014. Optimal retirement with increasing longevity. Scandinavian Journal of Economics 116(3): 838-858.

Boucekkine, R., D. de la Croix and O. Licandro 2003. Early mortality declines at the dawn of modern growth. Scandinavian Journal of Economics 105: 401-418.

Braakmann, N. 2011. The causal relationship between education, health, and health related behaviour: evidence from a natural experiment in England. Journal of Health Economics 30: 753-763.

Brown, D.C., M.D. Hayward, J.K. Montez, R.A. Hummer, C.-T. Chiu and M.M. Hidajat 2012. The significance of education for mortality compression in the United States. Demography 49: 819-840.

Brunello, G., M. Fort, N. Schneeweis and R. Winter-Ebmer 2015. The causal effect of education on health: what is the role of health behaviors? Health Economics, Early View.

Cai, L. and J. Lubitz 2007. Was there compression of disability for older Americans from 1992 to 2003. Demography 44: 479-495. 
Cawley, J. and C.J. Ruhm 2011. The economics of risky health behaviors. In Handbook of health economics, Vol. 2, ch. 3, ed. M.V. Pauly, T.G. Mcguire and P.P. Barros. Elsevier.

Cervellati, M. and U. Sunde 2005. Human capital, life expectancy, and the process of development. American Economic Review 95(5): 1653-1672.

Cervellati, M. and U. Sunde 2013. Life expectancy, schooling, and lifetime labor supply: theory and evidence revisited. Econometrica 81(5): 2055-2086.

Cervellati, M. and U. Sunde 2015a. The economic and demographic transition, mortality, and comparative development. American Economic Journal: Macroeconomics 7(3): 189-225.

Cervellati, M. and U. Sunde 2015b. The effect of life expectancy on education and population dynamics. Empirical Economics 48(4): 1445-1478.

Clark, A.E. and F. Etile 2006. Don't give up on me: Spousal correlation in smoking behaviour. Journal of Health Economics 25: 958-978.

Clark, A.E. and F. Etile 2011. Happy house: spousal weight and individual well-being. Journal of Health Economics 30: 1124-1136.

Clark, A.E. and Y. Loheac 2007. "It wasn't me, it was them!" Social influences in risky behaviour by adolescents. Journal of Health Economics 26: 763-784.

Clark, D. and H. Royer 2013. The effect of education on adult mortality and health: evidence from Britain. American Economic Review 103: 2087-2120.

Cobb-Clark, D.A., S.C. Kassenboehmer and S. Schurer 2014. Healthy habits: the connection between diet, exercise and locus of control. Journal of Economic Behavior $\mathcal{F}$ Organization 98: $1-28$.

Contoyannis, P., A.M. Jones and N. Rice 2004. The dynamics of health in the British Household Panel Survey. Journal of Applied Econometrics 19: 473-503.

Conti, G. and C. Hansman 2013. Personality and the education-health gradient: a note on "Understanding health differences in behaviors by education". Journal of Health Economics 32: 480-485.

Cremieux, P.-Y., P. Ouellette and C. Pilon 1999. Health care spending as determinants of health outcomes. Health Economics 8: 627-639.

Crimmins, E.M. 2004. Trends in the health of the elderly. Annual Reviews of Public Health 25: 79-98.

Crimmins, E.M. and H. Beltran-Sanchez 2010. Mortality and morbidity trends: is there compression of morbidity? Journal of Gerontology 66B: 75-86.

Currie, J. and E. Moretti 2003. Mother education and the intergenerational transmission of human capital: evidence from college openings and longitudinal data. Quarterly Journal of Economics 118: 1495-1532.

Cutler, D.M. 2007. The lifetime costs and benefits of medical technology. Journal of Health Economics 26: 1081-1100.

Cutler, D.M. and A. Lleras-Muney 2010. Understanding differences in health behaviors by education. Journal of Health Economics 29: 1-28.

Cutler, D., A. Deaton and A. Lleras-Muney 2006. The determinants of mortality. Journal of Economic Perspectives 20: 97-120.

Costa, D. 1998. The evolution of retirement: An American history, 1880-1990. Chicago, IL: The University of Chicago Press. 
D'Albis, H., S.-H. Lau and M. Sanchez-Romero 2012. Mortality transition and differential incentives for early retirement. Journal of Economic Theory 147(1): 261-283.

Dalgaard, C.-J. and H. Strulik 2014. Optimal aging and death: understanding the Preston curve. Journal of the European Economic Association 12: 672-701.

De la Croix, D. and O. Licandro 1999. Life expectancy and endogenous growth. Economics Letters 65: 255-263.

De Walque, D. 2007. Does education affect smoking behaviors? Evidence using the Vietnam draft as an instrument for college education. Journal of Health Economics 27: 877-895.

Dow, W.H., T.J. Philipson and X. Sala-i-Martin 1999. Longevity complementarities under competing risks. American Economic Review 89: 1358-1371.

Ehrlich, I. 2000. Uncertain lifetime, life protection, and the value of life saving. Journal of Health Economics 19: 341-367.

Ehrlich, I. and H. Chuma 1990. A model of the demand for longevity and the value of life extension. Journal of Political Economy 98: 761-782.

Eichhorst, W. 2011. The transition from work to retirement. IZA Discussion Paper No. 5490.

Ferreira, P.C. and S. de A Pessôa 2007. The effects of longevity and distortions on education and retirement. Review of Economic Dynamics 10: 472-493.

Fichera, E. and M. Sutton 2011. State and self investments in health. Journal of Health Economics 30: 1164-1173.

Fletcher, J.M. 2012. Peer influences on adolescent alcohol consumption: evidence using an instrumental variable/fixed effect approach. Journal of Population Economics 25: 1265-1286.

Ford, E.S., et al. 2007. Explaining the decrease in U.S. deaths from coronary disease, 19802000. New England Journal of Medicine 356: 2388-2398.

Freedman, V.A., R.F. Schoeni, L.G. Martin and J.C. Cornman 2007. Chronic conditions and the decline in late-life disability. Demography 44: 459-477.

Fries, J.F. 1980. Aging, natural death and the compression of morbidity. New England Journal of Medicine 303: 130-135.

Garcia-Gomez, P., E. Schokkaert, T. van Ourti and T. Bago d'Uva 2014. Inequity in the face of death. Health Economics, Early View.

Gardner, J. and A. Oswald 2004. How is mortality affected by money, marriage, and stress? Journal of Health Economics 23: 1181-1207.

Gathmann, C., S. Reinhold and H. Jürges 2015. Compulsory schooling reforms, education and mortality in twentieth century Europe. Social Science $\mathcal{E}$ Medicine 127: 74-82.

Glied, S. and A. Lleras-Muney 2008. Technological innovation and inequality in health. Demography 45: 741-761.

Grimard, F. and D. Parent 2007. Education and smoking: were Vietnam war draft avoiders also more likely to avoid smoking? Journal of Health Economics 27: 896-926.

Grossman, M. 1972. On the concept of health capital and the demand for health. Journal of Political Economy 80: 223-255.

Grossman, M. 2008. The relationship between health and schooling. Eastern Economic Journal 34: 281-292.

Gruber, J. and D. Wise 1998. Social security and retirement: An international comparison. American Economic Review 88(2): 158-163. 
Gruber, J. and D.A. Wise 2004. Social security programs and retirement around the world: microestimation. Chicago: University of Chicago Press.

Gruenberg, E.M. 1977. The failure of success. Millbank Memorial Fund Quarterly (Health and Society) 55: 3-24.

Grundy, E. and A. Sloggett 2003. Health inequalities in the older population: the role of personal capital, social resources and socio-economic circumstances. Social Science $\mathcal{E}$ Medicine 56: 935-947.

Hall, R.E. and C.I. Jones 2007. The value of life and the rise in health spending. Quarterly Journal of Economics 122: 39-72.

Hansen, C.W. and L. Lonstrup 2012a. Can higher life expectancy induce more schooling and earlier retirement? Journal of Population Economics 25(4): 1249-1264.

Hansen, C.W. and L. Lonstrup 2012b. Increasing life expectancy and the fall and rise in the retirement age, mimeo.

Hansen, C.W. 2013. Life expectancy and human capital: Evidence from the international epidemiological transition. Journal of Health Economics 32(6): 1142-1152.

Harris, J.E. and B.G. Lopez-Valcarcel 2008. Asymmetric peer effects in the analysis of cigarette smoking among young people in the United States, 1992-1999. Journal of Health Economics 27: 249-264.

Harris, K.M. 2010. An integrative approach to health. Demography 47: 1-22.

Hayward, M.D., R.A. Hummer and I. Sasson 2015. Trends and group differences in the association between educational attainment and U.S. adult mortality: implications for understand education's causal influence. Social Science $\mathcal{E}$ Medicine 127: 8-18.

Hazan, M. 2009. Longevity and lifetime labor supply: evidence and implications. Econometrica 77(6): 1829-1863.

Hazan, M. 2012. Life expectancy and schooling: new insights from cross-country data. Journal of Population Economics 25(4): 1237-1248.

Heijdra, B.J. and W.E. Romp 2009. Retirement, pensions and ageing. Journal of Public Economics 93: 586-604.

Jayachandran, S. and A. Lleras-Muney 2009. Life expectancy and human capital investments: evidence from maternal mortality declines. Quarterly Journal of Economics 124(1): 349-398.

Jones, A.M., J.A. Roemer and P. Rosa Dias 2014. Equalising opportunities in health through educational policy. Social Choice and Welfare 43: 521-545.

Jusot, F., S. Tubeuf and A. Trannoy 2013. Circumstances and efforts: how important is their correlation for the measurement of inequality in opportunity in health? Health Economics 22: $1470-1495$.

Kalemli-Ozcan, S., H.E. Ryder and D. Weil 2000. Mortality decline, human capital investment, and economic growth. Journal of Development Economics 62: 1-23.

Kalemli-Ozcan, S. and D. Weil 2010. Mortality change, the uncertainty effect, and retirement. Journal of Economic Growth 15(1): 65-91.

Kemptner, D., H. Jürges and S. Reinhold 2011. Changes in compulsory schooling and the causal effect of education on health: evidence from Germany. Journal of Health Economics 30: $340-354$. 
Kenkel, D., D. Lillard and A. Mathios 2006. The roles of high school completion and GED receipt in smoking and obesity. Journal of Labor Economics 24: 635-660.

Kuhn, M., S. Wrzaczek and J. Oeppen 2010. Recognizing progeny in the value of life. Economics Letters 107: 17-21.

Kuhn, M., S. Wrzaczek, A. Prskawetz and G. Feichtinger 2011. Externalities in a life cycle model with endogenous survival. Journal of Mathematical Economics 47: 627-641.

Kuhn, M., S. Wrzaczek, A. Prskawetz and G. Feichtinger 2015. Optimal choice of health and retirement in a life-cycle model. Journal of Economic Theory 158: 186-212.

Kunst, A.E., et al., 2005. Trends in socioeconomic inequalities in self-assessed health in 10 European countries. International Journal of Epidemiology 34: 295-305.

Lagerlof, N. 2003. From Malthus to modern growth: can epidemics explain the three regimes? International Economic Review 44(2): 755-777.

Lakdawalla, D.N., J. Bhattacharya and D.P. Goldman 2004. Are the young becoming more disabled. Health Affairs 23: 168-176.

Lazear, E.P. 1986. Retirement from the labor force. In Handbook of labor economics, ed. O. Ashenfelter and R. Layard, Vol. I, 305-355. Elsevier.

Lichtenberg, F.R. 2004. Sources of U.S. longevity increase, 1960-2001. Quarterly Review of Economics and Finance 44: 369-389.

Lleras-Muney, A. 2005. The relationship between education and adult mortality in the United States. Review of Economic Studies 72: 189-221.

Luke, D.A. and J.K. Harris 2007. Network analysis in public health: history, methods and applications. Annual Review of Public Health 28: 69-93.

Manton, K.G. 1982. Changing concepts of morbidity and mortality in elderly population. Millbank Memorial Fund Quarterly (Health and Society) 60: 183-244.

Martin, L.G., V.A. Freedman, R.F. Schoeni and P.M. Andreski 2009. Health and functioning among baby boomers approaching 60. Journal of Gerontology 64B: 378-389.

Martin, L.G., V.A. Freedman, R.F. Schoeni and P.M. Andreski 2010. Trends in disability and related chronic conditions among people ages fifty to sixty-four. Health Affairs 29: 725-731.

Martin, S., N. Rice and P.C. Smith 2008. Does health care spending improve health outcomes? Evidence from English programme budgeting data. Journal of Health Economics 27: 826-842.

Meara, E.R., S. Richards and D.M. Cutler 2008. The gap gets bigger: changes in mortality and life expectancy by education, 1981-2000. Health Affairs 27: 350-360.

Mincer, J. 1958. Investment in human capital and personal income distribution. Journal of Political Economy 66(4): 281-302.

Montez, J.K. and E.M. Friedman 2015. Introduction: educational attainment and health. Social Science $\mathcal{E}$ Medicine 127: 1-7.

Montez, J.K., R.A. Hummer and M.D. Hayward 2012. Educational attainment and adult mortality in the United States: a systematic analysis of functional form. Demography 49: 315-336.

Montez, J.K., R.A. Hummer, M.D. Hayward, H. Woo and R.G. Rogers 2011. Trends in the educational gradient of U.S. adult mortality from 1986 through 2006 by race, gender, and age group. Research on Aging 33: 145-171. 
Mora, T. and J. Gil 2013. Peer effects in adolescent BMI: evidence from Spain. Health Economics 22: 501-516.

Murphy, K.M. and R.H. Topel 2006. The value of health and longevity. Journal of Political Economy 114: 871-904.

Murphy, M., E. Grundy and S. Kalogiroua 2007. The increase in marital status differences in mortality up to the oldest age in seven European countries, 1990-99. Population Studies 61:287-298.

Nakajima, R. 2007. Measuring peer effects on youth smoking behaviour. Review of Economic Studies 74: 897-935.

OECD 2009. Society at a Glance 2009: OECD Social Indicators. Paris: OECD.

Oster, E., I. Shoulson and R. Dorsey 2013. Limited life expectancy, human capital and health investments. American Economic Review 103(5): 1977-2002.

Philipson, C. and A. Smith 2005. Extending working life: a review of the research literature. Department for Work and Pensions, Research Report No 299.

Powell, L.M., J.A. Tauras and H. Ross 2005. The importance of peer effects, cigarette prices and tobacco control policies for youth smoking behavior. Journal of Health Economics 24: 950-968.

Prettner, K. and D. Canning 2014. Increasing life expectancy and optimal retirement in general equilibrium. Economic Theory 56(1): 191-217.

Reinhold, S. and H. Jürges 2009. Secondary school fees and the causal effect of schooling on health behavior. Health Economics 19: 994-1001.

Restuccia, D. and G. Vandenbroucke 2013. A century of human capital and hours. Economic Inquiry 51(3): 1849-1866.

Restuccia, D. and G. Vandenbroucke 2014. Explaining educational attainment across countries and over time. Review of Economic Dynamics 17(4): 824-841.

Rockwood, K. and A. Mitnitski 2007. Frailty in relation to the accumulation of deficits. Journal of Gerontology 62A: 722-727.

Rosa Dias, P. 2009. Inequality of opportunity in health: evidence from a UK cohort study. Health Economics 18: 1057-1074.

Rosa Dias, P. 2010. Modelling opportunity of health under partial observability of circumstances. Health Economics 19: 252-264.

Sanchez-Romero, M., H. d'Albis and A. Prskawetz 2015. Education, lifetime labor supply, and longevity improvements. Conference Paper - Beiträge zur Jahrestagung des Vereins für Socialpolitik 2015: Ökonomische Entwicklung - Theorie und Politik - Session: Labor Supply, No. B18-V1.

Shepard, D.S. and R.J. Zeckhauser 1984. Survival versus consumption. Management Science 30: 423-439.

Smith, K.P. and N.A. Christakis 2008. Social networks and health. Annual Review of Sociology 34: 405-429.

Soares, R. 2005. Mortality reductions, educational attainment and fertility choice. American Economic Review 95(3): 580-601.

Soares, R. 2006. The effect of longevity on schooling and fertility: evidence from the Brazilian Demographic and Health Survey. Journal of Population Economics 19: 71-97. 
Soares, R. and B.L.S. Falcao 2008. The demographic transition and the sexual division of labor. Journal of Political Economy 116(6): 1058-1104.

Strauss, J. and D. Thomas 2007. Health over the life course. In: Handbook of Development Economics, Vol. 4, ch. 54, ed. T.P. Schultz and J.A. Strauss. Elsevier.

Strulik, H. 2015. Frailty, mortality, and the demand for medical care. Journal of the Economics of Ageing, in press.

Strulik, H. and K. Werner 2012. Life expectancy, labor supply, and long-run growth: Reconciling theory and evidence. University of Goettingen: Cege Discussion Paper 140.

Trannoy, A., S. Tubeuf, F. Jusot and M. Deveaux 2010. Inequality of opportunities in health in France: a first pass. Health Economics 19: 921-938.

Trogdon, J.G., J. Nonnemaker and J. Pais 2008. Peer effects in adolescent overweight. Journal of Health Economics 27: 1388-1399.

Van Baal, P., P. Obulqasim, W. Brouwer, W. Nusselder and J. Mackenbach 2013. The influence of health care spending on life expectancy. Netspar Panel Paper 35.

Wenger, G.C., A. Scott and N. Patterson 2000. How important is parenthood? Childlessness and support in old age in England. Ageing and Society 20: 161-182. 